\title{
La internacionalización de la universidad: debates globales, acciones regionales
}

\author{
María Luz Prados'
}

\begin{abstract}
PERROTTA, Daniela. La internacionalización de la universidad: debates globales, acciones regionales. Los Polvorines: Universidad Nacional de General Sarmiento; Buenos Aires: Instituto de Estudios y Capacitación (IEC-CONADU), 2016. 112p.
\end{abstract}

La obra fue escrita por Daniela Perrota, titulada La internacionalización de la universidad: debates globales, acciones regionales, publicada por la Universidad Nacional de General Sarmiento e Instituto de Estudios y Capacitación (IEC-CONADU), 2016. La autora es doctora en ciencias sociales por la Facultad Latinoamericana de Ciencias Sociales (FLACSO), Argentina, magister en ciencias sociales con mención en educación por la misma institución y licenciada en ciencias políticas por la Universidad Nacional de Buenos Aires, Argentina. Es docente e investigadora de las Facultades de Ciencias Sociales y de Filosofía y Letras de la Universidad Nacional de Buenos Aires.

En su libro la autora parte de la constatación de que en la actualidad la internacionalización posee un lugar central en los discursos sobre la universidad, en las políticas científicas y tecnológicas así como en las políticas universitarias y en las prácticas de las instituciones y de los actores de la educación superior. Incluso afirma que se enuncia la internacionalización como una de las nuevas misiones de las universidades, que se suma a las tradicionales: extensión, investigación y formación.

La relevancia adquirida por el fenómeno de la internacionalización se debe a varios procesos entre los cuales la autora destaca: el auge del Estado neoliberal, una economía basada en el conocimiento, el crecimiento del capitalismo trasnacional, la utilización del inglés como lengua franca y la aparición de nuevas tecnologías de la información y la comunicación. Entonces, dicho fenómeno adquiere, en el contexto actual, un carácter novedoso que se diferencia de experiencias anteriores de relacio-

Universidad Nacional de Rosario, Rosario, Santa Fe, Argentina. 
namiento internacional de la universidad y que sitúa su intensificación en la década del 90, producto de específicas políticas de internacionalización de la universidad.

Perrotta centra su análisis de las formas actuales que adquiere la internacionalización de la universidad desde una perspectiva histórica articulando los enfoques de la economía política internacional y la sociología crítica de la educación superior, con el explícito propósito de aportar a un campo de reciente conformación: los estudios de la internacionalización de la educación superior. Asimismo, busca contribuir al debate público sobre la universidad en el siglo XXI en América Latina y el Caribe.

El libro está estructurado en dos partes: una primera en la que se realiza una presentación del proceso de internacionalización y una segunda en la que se realiza un estudio de los regionalismos sudamericanos y las políticas para la educación superior.

En la primera parte se hace foco en definir y caracterizar el fenómeno de la internacionalización de la universidad. Se realiza un análisis de las diferentes definiciones de internacionalización arribando a la idea de que constituye un fenómeno complejo y multidimensional. Tal fenómeno es caracterizado en sus dimensiones actuales a partir de un pormenorizado análisis estadístico de fuentes.

La dinámica de la movilidad estudiantil en el mundo, la tasa de movilidad saliente y los principales destinos es estudiada a partir de fuente estadísticas elaboradas por el Instituto de Estadísticas de la Organización de las Naciones Unidas para la Educación, la Ciencia y la Cultura (UNESCO). Como fuente de análisis de la evolución de las exportaciones e importaciones de servicios educativos universitarios entre las décadas de los 90 y los dos mil se utilizan fuentes secundarias y documentos de organismos internacionales arribando así al análisis de la conformación de lo que Perrotta denomina como mercado académico global. Así se realiza un interesantísimo análisis de las regulaciones del mercado académico y de otros servicios de educación superior que se desprenden de tratados y acuerdos promovidos por diferentes organismos internacionales. Entonces, se indaga en los modos de provisión de servicios educativos que son promovidos por tales actores y en cómo inciden en un determinado modelo de internacionalización.

En la segunda parte se analizan los regionalismos sudamericanos y sus agendas de política regional para la educación superior. La autora parte de la caracterización de que en la región existe un solapamiento entre acuerdos de integración regional que representan proyectos políticos de regiones diferentes. Estos proyectos implican divergentes tendencias de internacionalización de la universidad. Tendencias que abrevan en tres modelos: en la internacionalización de estatus quo, en una internacionalización revisionista (incorpora algunas críticas al modelo anterior) y en la internacionalización rupturista (ruptura frente al modelo hegemónico de internacionalización).

A nuestro parecer, esta obra certeramente contribuye al debate público sobre la universidad en el siglo XXI en América Latina y el Caribe. Tal contribución se expresa en una tesis central que consideramos fundamental a la hora de debatir qué proyectos de universidad son necesarios para construir sociedades más justas e igualitarias: cómo determinadas formas de internacionalización inciden en proyectos de universidad. 
Perrotta enuncia dos formas de internacionalización: las hegemónicas y las alternativas. Las primeras corresponden a lo que la autora denomina como modelo de internacionalización fenicia y las segundas al modelo de internacionalización solidaria. Estas formas divergentes de encaminar la internacionalización se sustentan en modos de concebir la educación, el conocimiento y las formas de relacionamiento universidad-Estado. La autora aclara que tales modelos no existen en la realidad como formas "puras" sino que son más bien modelos analíticos.

Entonces, a nuestro parecer, el aporte sustancial que realiza la autora es hacer visible cómo las diversas formas de internacionalización abrevan en proyectos de universidad lo cual constituye un campo de poder atravesado por tensiones y disputas. En tal campo el regionalismo sudamericano aparece como un mojón desde el cual pensar una específica "posición latinoamericana". Así, en nuestros países latinoamericanos aparecen experiencias que promueven formas solidarias de internacionalización, con una clara vocación contrahegemónica, y que constituyen una apuesta a cimentar el sistema de educación superior en principios de solidaridad, igualdad y justicia social.

Finalmente, la obra de Perrotta constituye un gran aporte para la elaboración de políticas públicas en el campo mencionado al marcar con gran claridad cuál es el nudo del debate y la imbricación entre formas de internacionalización, concepciones de educación y del conocimiento.

\section{REFERENCIA}

Perrotta, D. La internacionalización de la universidad: debates globales, acciones regionales. Los Polvorines: Universidad Nacional de General Sarmiento; Buenos Aires: Instituto de Estudios y Capacitación (IEC-CONADU), 2016.

\section{SOBRE LA AUTORA}

María Luz Prados es titulada en ciencias de la educación por la Universidad Nacional de Rosario (Argentina). Profesora de la misma institución. E-mail: maluzprados@hotmail.com 